\title{
Formation Pathways of Mono- to Octa-Chlorinated Dibenzo-p-dioxins and Dibenzofurans in Main Organochemical Industries
}

\author{
Ying Han, Wenbin Liu,* Wenxiao Pan, Pu Wang, Zhenyu Tian, Yuyang Zhao, Mengjing Wang, \\ Xuebin Chen, Xiao Liao, and Minghui Zheng
}

State Key Laboratory of Environmental Chemistry and Ecotoxicology, Research Center for Eco-Environmental Sciences, Beijing 100085, China

\begin{abstract}
The concentrations and formation pathways of mono- to octa-chlorinated dibenzo-p-dioxins (PCDDs) and dibenzofurans (PCDFs) were investigated in main organochemical industries. High levels of PCDDs and PCDFs were detected. The total concentrations of $27 \mathrm{PCDD} / \mathrm{F}$ congeners in chloranil, 2,4-D, and 1,4-dichlorobenzene were $5302397 \pm$ $8944449,20963 \pm 15908$, and $242 \pm 67$ pg g $^{-1}$, respectively, and the less-chlorinated PCDD/F levels were $12006 \pm 20155$, $9536 \pm 5594$, and $195 \pm 94 \mathrm{pg} \mathrm{g}^{-1}$, respectively. The distribution trends of less and more chlorinated PCDD/Fs were similar in different chemical plants because of their similar formation pathways, which may also be related to the degree of chlorination of chemical products and purification processes.

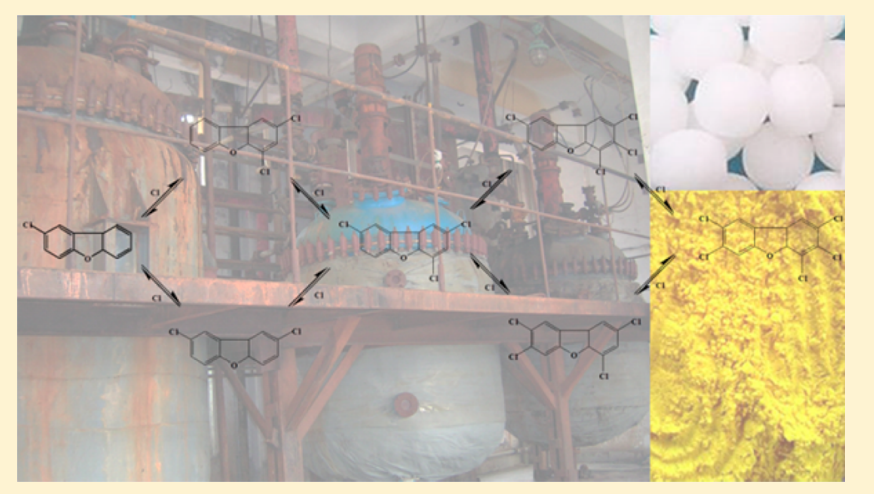
1,2,3,4-TeCDF and 2,4,8-TrCDF were selected as model molecules to calculate the bond dissociation energy, showing that 2MCDF, 3-MCDF, and 2,8-DCDF are more easily formatted as shown by the analytical results. The formation pathways of less to more chlorinated PCDFs are proposed to explain why 2-MoCDF, 2,8-DiCDF, 2,4,8-TrCDF, and 2,3,4,7,8-PeCDF are the dominant congeners and to explain why $2,3,4,7,8-\mathrm{PeCDF}$ is the largest contributor of I-TEQs in most studies.
\end{abstract}

\section{INTRODUCTION}

Persistent organic pollutants (POPs) have become a global environmental problem because of their environmental properties such as toxicity, persistence, bioaccumulation, and global dispersion. Polychlorinated dibenzo- $p$-dioxins (PCDDs) and polychlorinated dibenzofurans (PCDFs) are semivolatile compounds; they are hazardous pollutants and are formed as unintentional POPs during many industrial activities, such as combustion processes, sintering processes, ferrous and nonferrous production, and chemical industries. Especially in some organochemical industries, high levels of PCDD/Fs are detected as impurities. ${ }^{1-11}$ Although some kinds of chemicals, such as polychlorinated biphenyls, pentachlorophenol, and sodium pentachlorophenate, have been controlled in most countries since the 1970s, organic chemicals, for example, chloranil, 2,4-D (including 2,4-dichlorophenoxyacetic acid, 2,4dichlorophenoxyacetic acid butyl ester, etc.), chlorobenzene, etc., are still important emission sources of PCDD/Fs globally because of their enormous production and use in many countries.

Chloranil, 2,4-D, and chlorobenzene are the main chemical dioxin sources listed in the dioxin toolkit drafted by the United Nations Environment Program. Chloranil is mainly used as a fungicide, a pesticide, and a polymer intermediate and can also serve as an oxidant in organic synthesis, especially dye synthesis. 2,4-D, a well-known herbicide, is widely used against broad-leaf weeds in rice, wheat, and pastures, or as a plant growth regulator. 2,4-D derivatives are major herbicides and are cheap and highly efficient. 1,4-Dichlorobenzene is mainly used for the production of anti-moth agents, air deodorizers, dyes, pharmaceuticals, and soil disinfectants. The production processes for these chemicals involve several steps, typically including chlorination, oxidation, and purification. The dioxin formation mechanism in these production processes may be similar, because phenols or benzenes are the raw materials for producing the intermediates that are then chlorinated to chloranil, 2,4-D acid, and 2,4-D butyl ester with catalysis of Lewis acid. $^{12-14}$

The previous studies focused on the concentrations of 17 highly chlorinated PCDD/F (2,3,7,8-substituted PCDD/Fs) congeners, and the concentrations and formation of less chlorinated PCDD/Fs (mono- to tri-CDD/Fs; mono = Mo; di $=\mathrm{Di}$; and tri $=\mathrm{Tr}$ ) have not been studied. ${ }^{2,11,15}$ A recent study in Korea showed that Mo- to Tr-CDFs accounted for more than $95 \%$ of the total PCDF concentrations in serum samples collected from municipal solid waste incinerator operators and nearby residents. The results emphasized the possible

Received: June 4, 2015

Revised: August 16, 2015

Accepted: August 24, 2015

Published: August 24, 2015 

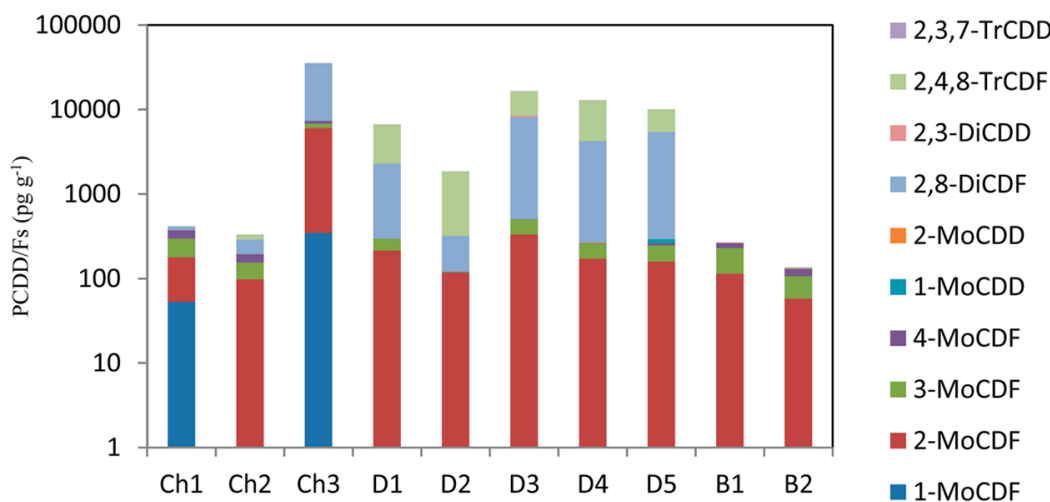

(a)

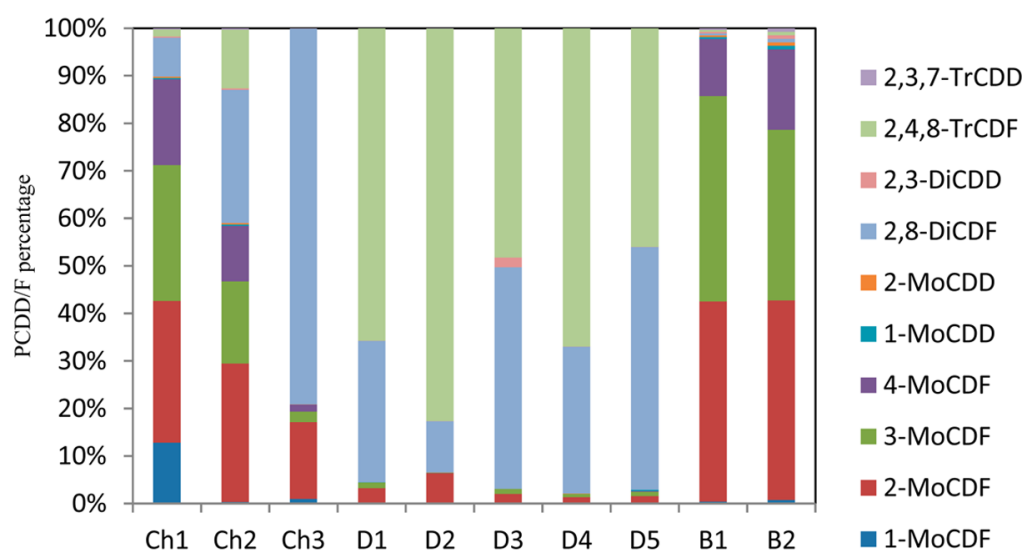

(b)

Figure 1. (a) PCDD/F amounts and (b) contribution of each congener in percentage in the samples.

significant impact that less chlorinated PCDD/Fs may have on humans and the environment, which have been almost ignored. Less chlorinated PCDD/Fs are prone to partitioning in gas phases and may spread widely in the environment, because they have vapor pressures higher than those of more chlorinated PCDD/Fs. ${ }^{2}$ It is therefore important to obtain a full picture of Mo- to OCDD/Fs and to explore the formation pathway of $\mathrm{PCDD} / \mathrm{Fs}$ that formed in widely used chemicals and then were emitted into the environment. In addition, the impurities of $\mathrm{PCDD} / \mathrm{Fs}$ in these chemicals may increase the health risk for the workers and users, as they are widely used in the world. The production processes of these chemicals are similar in most countries; therefore, the results of this study could be disseminated globally and contribute to the risk evaluation and control of PCDD/F impurities in organochemicals to protect human and environmental health. ${ }^{16,19}$

\section{MATERIALS AND METHODS}

2.1. Sample Collection. China has the largest organochemical industry in the world; however, the kinds of production processes of 2,4-D, chloranil, and 1,4-dichlorobenzene are limited, which are produced in only dozens of chemical plants. In this study, 10 plants were chosen as typical organochemical producers. The product samples of chemicals were collected from these plants, the purities of which vary depending on the quality of the products and their intended use.

Three chloranil samples were collected from different plants, in which the purity of chloranil products varied dramatically because of the different uses of the products. Sample Ch1, used as an intermediate in pharmaceutical products, was extracted and highly purified, giving a product with a purity of $99 \%$. The purity of Ch2 was $96 \%$. Sample Ch3, of only $90 \%$ purity, was mainly used as an intermediate in dye and pesticide products. Two 2,4-D acid samples, i.e., D1 and D2, were obtained; D1 was formed from phenoxyacetic acid, and D2 was formed from 2,4-dichlorophenol. Three 2,4-D butyl ester samples, D3-D5, were obtained. Two 1,4-dichlorobenzene samples, B1 and B2, mainly used as anti-moth agents, were collected from two plants. The samples were stored at $20{ }^{\circ} \mathrm{C}$ prior to their analysis.

2.2. Sample Extraction and Analysis. The pretreatment and analyses of the Mo- to O-CDD/Fs were performed using standard method EPA-1613, which had been described previously. $9,12,18-25$ Briefly, the samples were mixed with ${ }^{13} \mathrm{C}$ labeled PCDD/Fs and then extracted. The chloranil samples were Soxhlet extracted with hexane and dichloromethane [1:1 $(\mathrm{v} / \mathrm{v})]$; the 2,4-D acid samples were dissolved in a sodium hydroxide solution and then extracted with hexane, and the 2,4D butyl ester and 1,4-dichlorobenzene samples were extracted with hexane directly.

With regard to the analysis of Te- to OCDD/Fs, all samples were spiked with known amounts of ${ }^{13} \mathrm{C}$-labeled internal standard (EPA-1613LCS; Wellington Laboratories), including $16 \mathrm{PCDD} / \mathrm{F}$ congeners (2,3,7,8-TCDD, 2,3,7,8-TCDF, 1,2,3,7,8-PeCDD, 1,2,3,7,8-PeCDF, 2,3,4,7,8-PeCDF, 1,2,3,4,7,8-HxCDD, 1,2,3,6,7,8-HxCDD, 1,2,3,7,8,9-HxCDD, $1,2,3,4,7,8-\mathrm{HxCDF}, \quad 1,2,3,6,7,8-\mathrm{HxCDF}, \quad 1,2,3,7,8,9-\mathrm{HxCDF}$, 2,3,4,6,7,8-HxCDF, 1,2,3,4,6,7,8-HpCDD, 1,2,3,4,6,7,8HpCDF, 1,2,3,4,7,8,9-HpCDF, and OCDD), before extraction. Then the extracts were concentrated and cleaned up with 

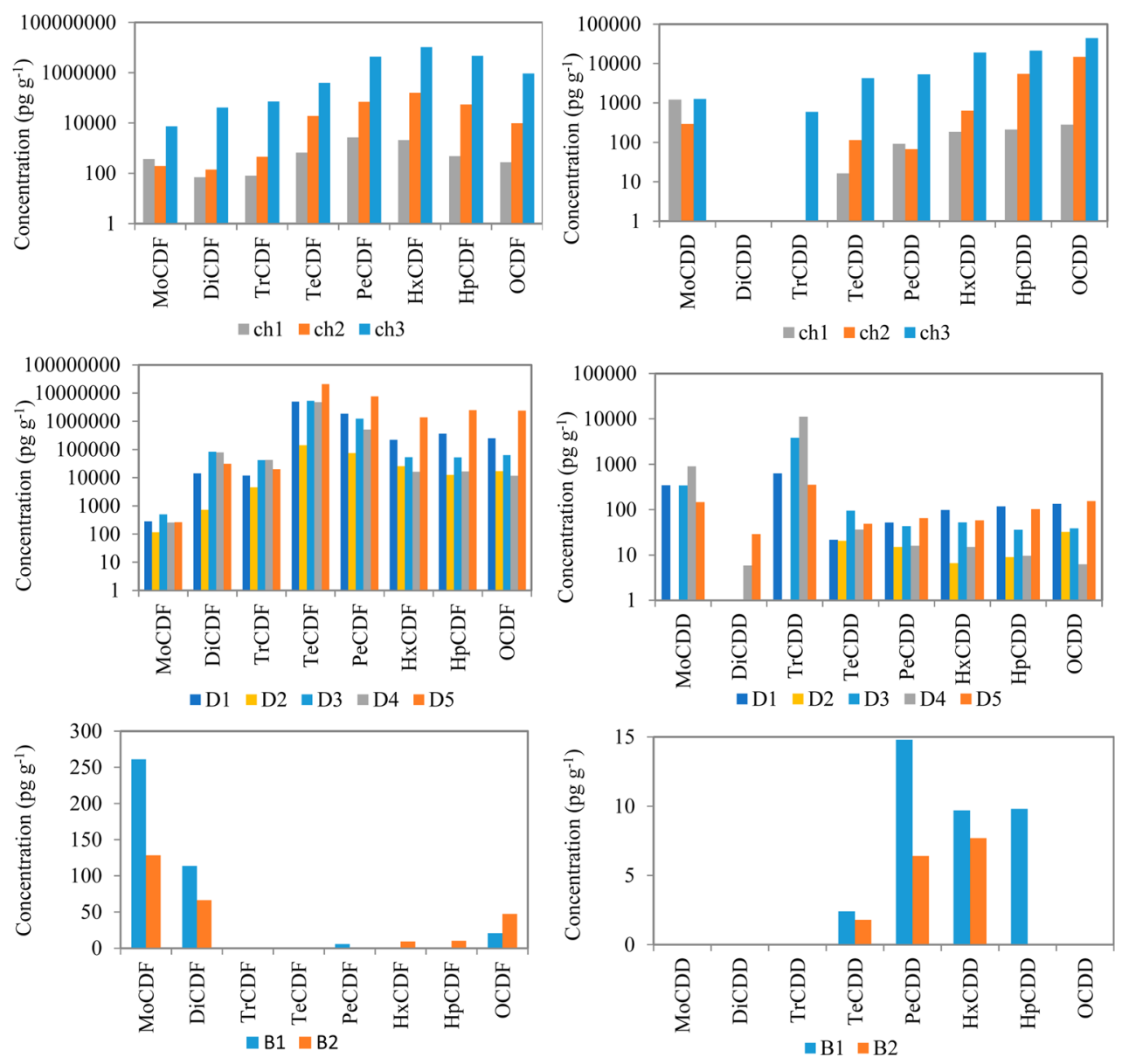

Figure 2. Homologous profiles of PCDFs and PCDDs in the samples.

multilayer silica columns and a basic alumina column. The final extracts were spiked with ${ }^{13} \mathrm{C}$-labeled $\mathrm{PCDD} / \mathrm{F}$ standards for quantification prior to instrumental analysis.

For the qualitative and quantitative analyses of Mo- to Tr$\mathrm{CDD} / \mathrm{Fs}$, a ${ }^{13} \mathrm{C}$-labeled internal standard (EDF-4955; Cambridge Isotope Laboratories) containing six congeners (2MoCDD, 2,3-DiCDD, 2,3,7-TrCDD, 2-MoCDF, 2,8-DiCDF, and 2,4,8-TrCDF) was added before extraction, and an extract aliquot was concentrated and purified using a multilayer silica gel column eluted with $100 \mathrm{~mL}$ of hexane. The extract evaporated and separated on an $8 \mathrm{~g}$ basic alumina column eluted with $80 \mathrm{~mL}$ of $2 \%$ dichloromethane in hexane, and then $150 \mathrm{~mL}$ of $12 \%$ dichloromethane in hexane. The latter fraction contained the Mo- to $\mathrm{Tr}-\mathrm{CDD} / \mathrm{Fs}$ and was concentrated to 40 $\mu \mathrm{L}$ of nonane under a nitrogen flow before instrumental analysis.

The Mo- to O-CDD/Fs were analyzed using an Agilent 6890 high-resolution gas chromatograph (Agilent Technologies, Santa Clara, CA) equipped with a DB-5 mass spectrometry (MS) column, coupled to a Waters Autospec Ultima highresolution mass spectrometer (Waters Corp., Milford, MA). The mass spectrometer had a resolution of at least 10000 and operated in selected ion monitoring mode. The recovery range for the 17 2,3,7,8-chlorinated PCDD/Fs was 67-149\%, and the recoveries of the $10 \mathrm{Mo}$ - to $\mathrm{Tr}-\mathrm{CDD} / \mathrm{F}$ congeners were between 41 and $93 \%$.

\section{RESULTS AND DISCUSSION}

3.1. Concentrations of Chlorinated PCDD/Fs. High levels of $\mathrm{PCDD} / \mathrm{Fs}$ in the samples were detected. The total concentrations of $27 \mathrm{PCDD} / \mathrm{F}$ congeners (10 less chlorinated and 17 more chlorinated congeners) in chloranil, 2,4-D, and 1,4-dichlorobenzene were $5302397 \pm 8944449,20963 \pm$ 15908 , and $242 \pm 67 \mathrm{pg} \mathrm{g}^{-1}$, respectively. High concentrations of less chlorinated $\mathrm{PCDD} / \mathrm{F}$ were also detected in the samples presented in Figure 1, showing significantly higher levels than other industries such as waste incineration. ${ }^{2}$ The less chlorinated $\mathrm{PCDD} / \mathrm{F}$ level in chloranil was $12006 \pm 20155 \mathrm{pg} \mathrm{g}^{-1}$. Four congeners of MoCDF were detected, but the concentrations were relatively low, ranging from 53.2 to $5690 \mathrm{pg} \mathrm{g}^{-1}$. The 2MoCDF level in Ch3 was slightly higher than that of the other congeners, which had concentrations of $<1000 \mathrm{pg} \mathrm{g}^{-1}$. Ch3 was different from the other two samples. The content of 2,8DiCDF was $27896 \mathrm{pg} \mathrm{g}^{-1}$, which was much higher than the levels of 2,8-DiCDF in Ch1 and Ch2. MoCDD and DiCDD were not detected in these three samples. Only 2,3,7-TrCDD was found in Ch3.

In 2,4-D samples, the less chlorinated PCDD/F concentration was $9536 \pm 5594 \mathrm{pg} \mathrm{g}^{-1}$. Almost no $1-\mathrm{MoCDF}$, 1MoCDD, 2,3-DiCDD, and 2,3,7-TrCDD was found in the 2,4$\mathrm{D}$ samples; however, high concentrations of 2,8-DiCDF and $2,4,8-\mathrm{TrCDF}$ were detected. The levels of 2,8 -DiCDF and 2,4,8-TrCDF changed from 199 and $7618 \mathrm{pg} \mathrm{g}^{-1}$, respectively, to 1524 and $8606 \mathrm{pg} \mathrm{g}^{-1}$, respectively. 


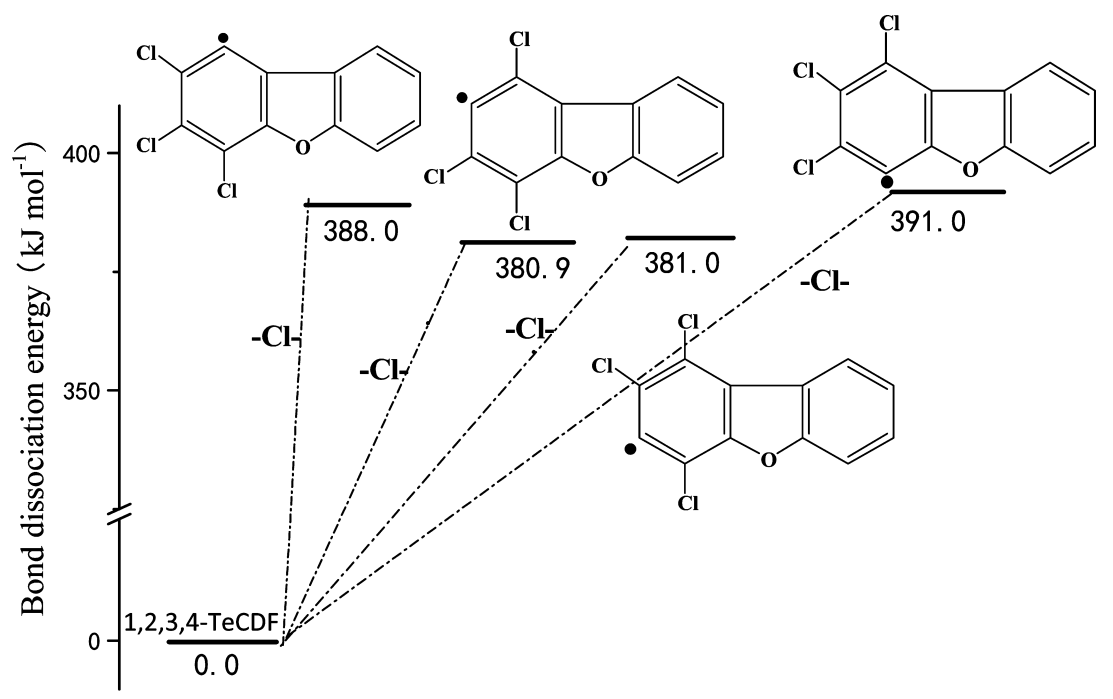

Figure 3. Bond dissociation energies of four $\mathrm{C}-\mathrm{Cl}$ bonds of $1,2,3,4-\mathrm{TeCDF}$.

The less chlorinated PCDD/F level in 1,4-dichlorobenzene was $195 \pm 94 \mathrm{pg} \mathrm{g}^{-1}$. Only 2-MCDF and 3-MCDF were detected in the 1,4-dichlorobenzene sample, with a concentration in the range of $48.5-116 \mathrm{pg} \mathrm{g}^{-1}$. Few of the less chlorinated PCDD congeners were detected, and only a small amount of MCDFs was found, which means that the amounts of dioxin impurities in the 1,4-dichlorobenzene samples were small.

3.2. Relationship between Less and More Chlorinated PCDD/Fs. The homologue profiles of the less and more chlorinated PCDD/Fs in 10 samples are shown in Figure 2.

As Figure 2 shows, the distributions of the less and more chlorinated PCDD/Fs are similar for each type of compound, although the concentrations of $\mathrm{PCDD} / \mathrm{F}$ homologues from different plants differ. The concentrations of PCDFs are generally higher than that of PCDDs, and the total concentrations of PCDFs are several orders higher than that of PCDDs.

Although the levels of less chlorinated PCDD/Fs in the three chloranil samples vary widely, the variations in PCDF homologues in chloranil present a nearly normal distribution, and the $\mathrm{HxCDF}$ content is highest. In addition, the concentrations of TeCDF, PeCDF, HpCDF, and OCDF are regularly distributed around $\mathrm{HxCDF}$. Besides, the level of PCDD/Fs negatively related to the product purity: the higher the degree of purification, the lower the content of PCDD/Fs. This is mainly because distillation purification can remove the PCDD/F impurities efficiently because of the high boiling point of PCDD/Fs.

The levels of PCDD/F homologues in 2,4-D were generally higher. The TeCDF content was the highest. The levels of DiCDF and TrCDF were similar and much greater than that of MoCDF; they dominated the less chlorinated PCDF homologues in 2,4-D. For the 2,4-D and 2,4-D butyl ester samples, the highest concentrations were found in the 2,4-D butyl ester samples, as a result of further chlorination during the production of 2,4-D butyl ester from 2,4-D in the presence of a ferric chloride catalyst and chlorine.

The 1,4-dichlorobenzene samples had higher concentrations of less chlorinated PCDF homologues than of more chlorinated PCDD/F homologues. Mo- and Di-CDF dominated the dioxin homologues in the 1,4-dichlorobenzene samples and may be released into the environment in applications of 1,4dichlorobenzene.

The degree of chlorination of a sample is defined as the total number of chlorine atoms in the total concentration. On one hand, the degree of chlorination of PCDD/Fs may be positively related to the degree of chlorination of the chemical products. From Figure 2, it can be seen that the intensity of the peak of homologues of PCDD/Fs in chloranil, 2,4-D, and 1,4dichlorobenzene decreased obviously, in which theree are four, two, and two chlorine atoms, respectively. On the other hand, the degree of chlorination of PCDD/Fs may be related to the purification process of producing the chemicals. The degrees of chlorination for Ch1, Ch2, and Ch3 are 4.77, 6.00, and 6.05, respectively; these values positively correlated with the $\mathrm{PCDD} / \mathrm{F}$ concentrations. Compared with the more chlorinated $\mathrm{PCDD} / \mathrm{Fs}$ congeners, the less chlorinated compounds with lower melting and boiling points are more difficult to remove and tend to persist in the final products, which result in lower degrees of chlorination. Thus, purification processes should be modified not only to decrease the amounts of more chlorinated PCDD/F impurities but also to control the release of less chlorinated PCDD/F congeners, reducing the potential risks posed to human health and environmental ecosystems.

3.3. Proposed Formation Pathway of PCDD/Fs. The bond dissociation energy (BDE) represents the reaction enthalpy of homolytic bond cleavage. 1,2,3,4-TeCDF was selected as a model molecule to calculate the BDEs of 1-, 2-, 3-, and 4-C-Cl. According to eq 1, we compared the bond energies at different sites and assessed the possibility of compound formation. The calculations were performed with the Gaussian 09 program package, using the BB1K/6-311G(d,p) method.

$$
\mathbf{A}-\mathbf{B} \rightarrow \mathbf{A} \cdot(g)+\mathbf{B} \cdot(g)
$$

The BDEs of 1-, 2-, 3-, and 4-C-Cl were 388, 380.9, 381, and $391 \mathrm{~kJ} \mathrm{~mol}^{-1}$, respectively (Figure 3 ). If the BDE is smaller, the generation or destruction of the bond is easy to accomplish; therefore, $2-\mathrm{C}$ and 3-C in the molecular model are more easily chlorinated or dechlorinated. According to the data in Figure 1, the proportions of 1-MoCDF, 2-MoCDF, 3-MoCDF, and 4MoCDF in the total MoCDFs were 1.9 $\pm 4.6,61.3 \pm 19.5,28.4$ \pm 13.2 , and $8.4 \pm 8.6 \%$, respectively, showing that the analytical results and the $\mathrm{BDE}$ calculation results are almost consistent. 


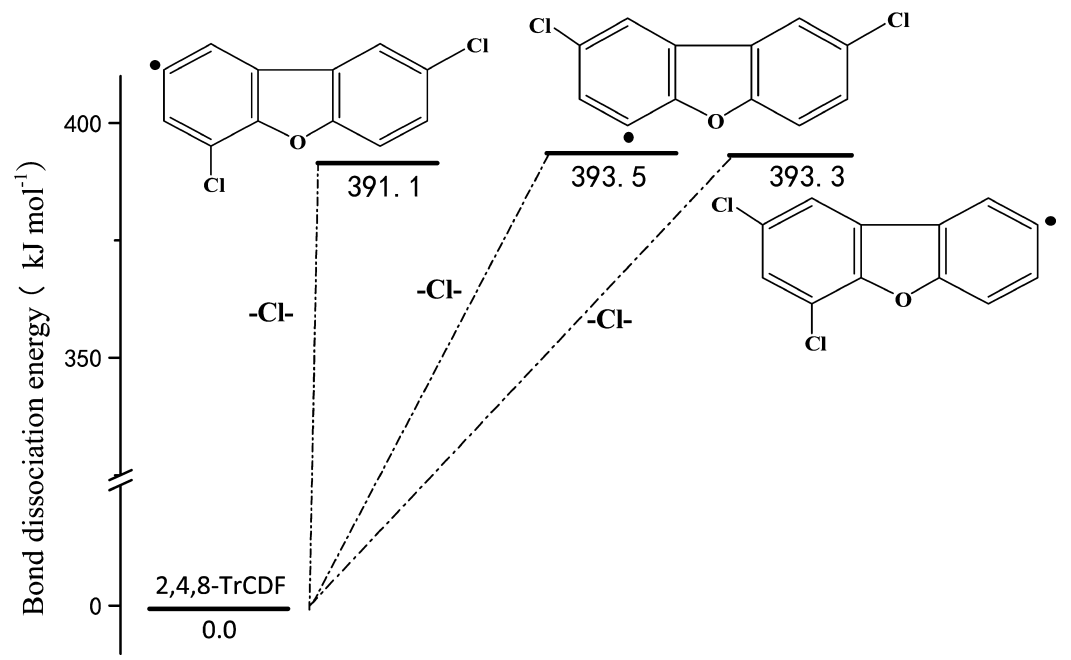

Figure 4. Bond dissociation energies of three $\mathrm{C}-\mathrm{Cl}$ bonds of 2,4,8-TeCDF.

The existence of greater steric hindrance in 1- and 4-C-Cl would affect the generation or destruction of the bond in these two positions. The contents of $2-\mathrm{MoCDF}$ and 3-MoCDF were far higher than those of 1-MoCDF and 4-MoCDF because of their obviously lower BDEs. The fraction of 2-MoCDF was higher than that of 3-MoCDF because of its lower BDE, while the analytical results and the $\mathrm{BDE}$ calculation results of 1MoCDF and 4-MoCDF are inconsistent because of the variation of the analytical results caused by the low concentrations.

We took 2,4,8-TrCDF, with a higher concentration in samples, as a model molecule and used eq 1 to calculate the BDEs of 2-, 4-, and 8-C-Cl and then investigated the formation mechanism of $2,4,8-\operatorname{TrCDF}$. The calculations were performed with the Gaussian 09 program package, using the BB1K/6$311+\mathrm{G}(3 \mathrm{df}, 2 \mathrm{p}) / / \mathrm{BB} 1 \mathrm{~K} / 6-311 \mathrm{G}(\mathrm{d}, \mathrm{p})$ method. The BDEs of 2-, 4-, and 8-C-Cl were 391.1, 393.5, and $393.3 \mathrm{~kJ} \mathrm{~mol}^{-1}$, respectively (Figure 4). The results showed that $2-\mathrm{C}-\mathrm{Cl}$ has the smallest BDE and the 4- and 8-C-Cl BDEs are similar to each other. Furthermore, we optimized the 2,4-DCDF and 2,8DCDF configurations and calculated their energies. The energy of $2,8-\mathrm{DCDF}$ is $7.9 \mathrm{~kJ} \mathrm{~mol}^{-1}$ lower than that of $2,4-\mathrm{DCDF}$, suggesting that $2,8-\mathrm{DCDF}$ is easier to generate than $2,4-\mathrm{DCDF}$, which also can be illustrated by the data of the results; the content of 2,8-DiCDF in the whole DiCDF congeners occupied a high proportion of up to $61 \pm 11 \%$ in chloranil samples. On the basis of the data obtained in this study and previous studies, ${ }^{26-29}$ a proposed formation pathway from less to more chlorinated PCDFs is shown in Figure 5.

From Figure 5, it can be seen that $2-\mathrm{C}$ and $8-\mathrm{C}$ are symmetrical substitution positions, so $2,8-\mathrm{DiCDF}$ is the dominant congener in the DiCDFs because of the steric hindrance of chlorine atoms confirmed by the calculation result of BDE. Both 2,8-DiCDF and 2,4-DiCDF are easily chlorinated to $2,4,8$-TrCDF. In a further chlorination process, $2,4,8-\operatorname{TrCDF}$ can form two TeCDF congeners, namely, 2,3,6,8-TeCDF and $2,3,4,8-\mathrm{TeCDF}$, both of which are finally converted to $2,3,4,7,8$ PeCDF. Chlorination and dechlorination among these congeners are balancing processes, and they lead to 2MoCDF, 2,8-DiCDF, 2,4,8-TrCDF, and 2,3,4,7,8-PeCDF as dominant congeners, in agreement with the data from this study and previous studies. ${ }^{2}$ Additionally, as the toxic equivalent factor of $2,3,4,7,8-\mathrm{PeCDF}$ is 0.5 and with the

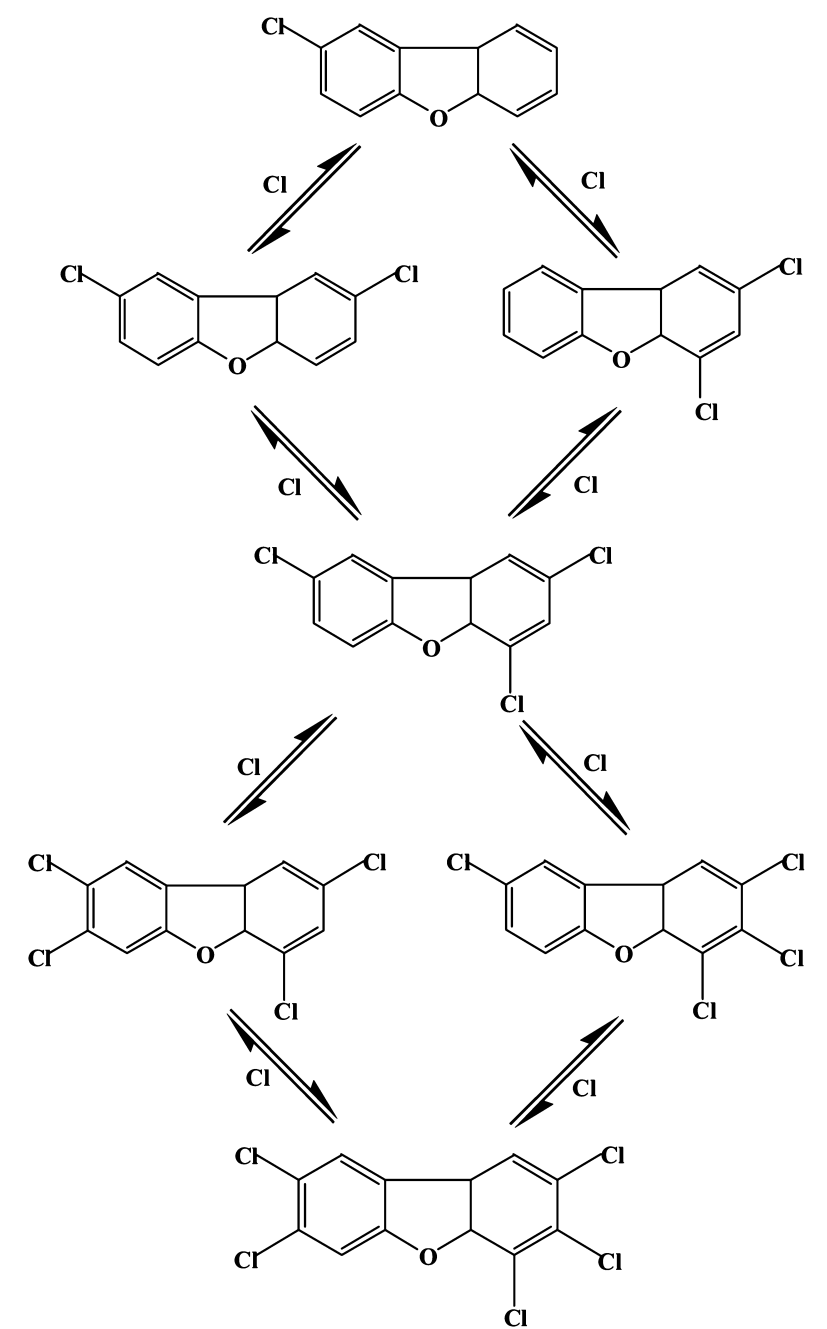

Figure 5. Proposed formation pathway of key PCDF congeners.

relatively higher levels of $2,3,4,7,8-\mathrm{PeCDF}$ in the $2,3,7,8$ substituted $\mathrm{PCDD} / \mathrm{F}$ congeners, 2,3,4,7,8-PeCDF may be the main contributor to the TEQs. In this study, the proportions of 2,3,4,7,8-PeCDF in total I-TEQs in chloranil and 2,4-D samples were $31.1 \pm 4.6$ and $38.4 \pm 18.7 \%$, respectively. Therefore, this formation pathway can also explain why the $2,3,4,7,8-\mathrm{PeCDF}$ is 
identified as the largest contributor to the I-TEQs in most dioxin sources.

\section{AUTHOR INFORMATION}

\section{Corresponding Author}

*Phone: 8610 62849356. Fax: 8610 62923563. E-mail: liuwb@rcees.ac.cn.

Notes

The authors declare no competing financial interest.

\section{ACKNOWLEDGMENTS}

This study was supported by the National 973 Program (2015CB453103 and 2011CB201500), Environmental Public Welfare Projects (201209019), and the National Natural Science Foundation of China (21477150 and 21321004).

\section{REFERENCES}

(1) Cortes, J.; Gonzalez, C. M.; Morales, L.; Abalos, M.; Abad, E.; Aristizabal, B. H.PCDD/PCDF and dl-PCB in the ambient air of a tropical Andean city: passive and active sampling measurements near industrial and vehicular pollution sources. Sci. Total Environ. 2014, 491-492, 67-74.

(2) Liu, W.; Tian, Z.; Li, H.; Xie, H.; Xiao, K.; Li, C.; Tang, C.; Zheng, M. Mono- to Octa-chlorinated PCDD/Fs in stack gas from typical waste incinerators and their implications on emission. Environ. Sci. Technol. 2013, 47 (17), 9774-80.

(3) Lin, X.; Yan, M.; Dai, A.; Zhan, M.; Fu, J.; Li, X.; Chen, T.; Lu, S.; Buekens, A.; Yan, J. Simultaneous suppression of PCDD/F and NO(x) during municipal solid waste incineration. Chemosphere 2015, 126, 60-6.

(4) Li, C.; Zheng, M.; Zhang, B.; Gao, L.; Liu, L.; Zhou, X.; Ma, X.; Xiao, K. Long-term persistence of polychlorinated dibenzo-p-dioxins and dibenzofurans in air, soil and sediment around an abandoned pentachlorophenol factory in China. Environ. Pollut. 2012, 162, 13843.

(5) Tang, F.; Ni, Y.; Zhang, H.; Li, Y.; Jin, J.; Wang, L.; Chen, J. A new cleanup method of dioxins in sediment using large volume injection gas chromatography online coupled with liquid chromatography. Anal. Chim. Acta 2012, 729, 73-9.

(6) Lundin, L.; Marklund, S. Thermal degradation of PCDD/F, PCB and HCB in municipal solid waste ash. Chemosphere 2007, 67 (3), 474-81.

(7) Lundin, L.; Marklund, S. Thermal Degradation of PCDD/F in Municipal Solid Waste Ashes in Sealed Glass Ampules. Environ. Sci. Technol. 2005, 39, 3872-3877.

(8) Zhang, H.; Zhao, X.; Ni, Y.; Lu, X.; Chen, J.; Su, F.; Zhao, L.; Zhang, N.; Zhang, X. PCDD/Fs and PCBs in sediments of the Liaohe River, China: levels, distribution, and possible sources. Chemosphere 2010, 79 (7), 754-62.

(9) Morales, L.; Dachs, J.; Gonzalez-Gaya, B.; Hernan, G.; Abalos, M.; Abad, E. Background concentrations of polychlorinated dibenzo-pdioxins, dibenzofurans, and biphenyls in the global oceanic atmosphere. Environ. Sci. Technol. 2014, 48 (17), 10198-207.

(10) Benisek, M.; Kukucka, P.; Mariani, G.; Suurkuusk, G.; Gawlik, B. M.; Locoro, G.; Giesy, J. P.; Blaha, L. Dioxins and dioxin-like compounds in composts and digestates from European countries as determined by the in vitro bioassay and chemical analysis. Chemosphere 2015, 122, 168-75.

(11) Park, H.; Park, E.; Chang, Y. S. Ten-year time trend of dioxins in human serum obtained from metropolitan populations in Seoul, Korea. Sci. Total Environ. 2014, 470-471, 1338-45.

(12) Liu, W.; Tao, F.; Zhang, W.; Li, S.; Zheng, M. Contamination and emission factors of $\mathrm{PCDD} / \mathrm{Fs}$, unintentional $\mathrm{PCBs}, \mathrm{HxCBz}$, $\mathrm{PeCBz}$ and polychlorophenols in chloranil in China. Chemosphere 2012, 86 (3), 248-51.

(13) Liu, W.; Li, H.; Tao, F.; Li, S.; Tian, Z.; Xie, H. Formation and contamination of $\mathrm{PCDD} / \mathrm{Fs}, \mathrm{PCBs}, \mathrm{PeCBz}, \mathrm{HxCBz}$ and polychlor- ophenols in the production of 2,4-D products. Chemosphere 2013, 92 (3), 304-8.

(14) Liu, W.; Zheng, M.; Wang, D.; Xing, Y.; Zhao, X.; Ma, X.; Qian, Y. Formation of PCDD/Fs and PCBs in the process of production of 1,4-dichlorobenzene. Chemosphere 2004, 57 (10), 1317-23.

(15) Hung, P. C.; Chang, S. H.; Lin, S. H.; Buekens, A.; Chang, M. B. Pilot tests on the catalytic filtration of dioxins. Environ. Sci. Technol. 2014, 48 (7), 3995-4001.

(16) Hoang, T. T.; Traag, W. A.; Murk, A. J.; Hoogenboom, R. L. Levels of polychlorinated dibenzo-p-dioxins, dibenzofurans (PCDD/ Fs) and dioxin-like PCBs in free range eggs from Vietnam, including potential health risks. Chemosphere 2014, 114, 268-74.

(17) Ryan, J. J.; Rawn, D. F. Polychlorinated dioxins, furans (PCDD/ $\mathrm{Fs}$ ), and polychlorinated biphenyls (PCBs) and their trends in Canadian human milk from 1992 to 2005. Chemosphere 2014, 102, $76-86$.

(18) Schecter, A.; Birnbaum, L.; Ryan, J. J.; Constable, J. D. Dioxins: an overview. Environ. Res. 2006, 101 (3), 419-28.

(19) Pan, J.; Yang, Y. L.; Chen, D. Z.; Xu, Q.; Tang, H.; Li, Y.; Nie, L. M.; Jiang, K.; Xi, D. L. Distribution characteristics and source analysis of dioxins in sediments and mussels from Qingdao coastal sea. Chemosphere 2008, 70 (9), 1699-706.

(20) Weidemann, E.; Lundin, L. Behavior of PCDF, PCDD, PCN and PCB during low temperature thermal treatment of MSW incineration fly ash. Chem. Eng. J. 2015, 279, 180-187.

(21) Weidemann, E.; Marklund, S.; Bristav, H.; Lundin, L. In-filter PCDF and PCDD formation at low temperature during MSWI combustion. Chemosphere 2014, 102, 12-7.

(22) Li, X.; Yan, M.; Yang, J.; Chen, T.; Lu, S.; Yan, J. PCDD/Fs in soil around a hospital waste incinerator: comparison after three years of operation. J. Environ. Sci. 2012, 24 (4), 699-703.

(23) Kim, K. S.; Lee, S. C.; Kim, K. H.; Shim, W. J.; Hong, S. H.; Choi, K. H.; Yoon, J. H.; Kim, J. G. Survey on organochlorine pesticides, $\mathrm{PCDD} / \mathrm{Fs}$, dioxin-like PCBs and HCB in sediments from the Han river, Korea. Chemosphere 2009, 75 (5), 580-7.

(24) Venkatesan, A. K.; Halden, R. U. Contribution of polybrominated dibenzo-p-dioxins and dibenzofurans $(\mathrm{PBDD} / \mathrm{Fs})$ to the toxic equivalency of dioxin-like compounds in archived biosolids from the U.S. EPA's 2001 national sewage sludge survey. Environ. Sci. Technol. 2014, 48 (18), 10843-9.

(25) L'Homme, B.; Scholl, G.; Eppe, G.; Focant, J. F. Validation of a gas chromatography-triple quadrupole mass spectrometry method for confirmatory analysis of dioxins and dioxin-like polychlorobiphenyls in feed following new EU Regulation 709/2014. J. Chromatogr. A 2015, 1376, 149-58.

(26) Tuppurainen, K.; Asikainen, A.; Ruokojärvi, P.; Ruuskanen, J. Perspectives on the Formation of Polychlorinated Dibenzo-p-dioxins and Dibenzofurans during Municipal Solid Waste (MSW) Incineration and Other Combustion Processes. Acc. Chem. Res. 2003, 36, 652-658.

(27) Ooi, T. C.; Lu, L. Formation and mitigation of PCDD/Fs in iron ore sintering. Chemosphere 2011, 85 (3), 291-9.

(28) Altarawneh, M.; Dlugogorski, B. Z.; Kennedy, E. M.; Mackie, J. C. Mechanisms for formation, chlorination, dechlorination and destruction of polychlorinated dibenzo-p-dioxins and dibenzofurans (PCDD/Fs). Prog. Energy Combust. Sci. 2009, 35 (3), 245-274.

(29) Kawamoto, K. Potential formation of PCDD/Fs and related bromine-substituted compounds from heating processes for ashes. $J$. Hazard. Mater. 2009, 168 (2-3), 641-8. 